\title{
UM OLHAR SOBRE O TRATO PEDAGÓGICO DA VARIAÇÃO LINGUÍSTICA NO LIVRO DIDÁTICO DE PORTUGUÊS
}

\author{
Evangelina Maria Brito de Faria* \\ Ewerton Ávila dos Anjos Luna**
}

\begin{abstract}
Resumo: Considerando relevantes reflexões sobre processos de transposição didática, mais especificamente as contribuições trazidas pelos estudos da Sociolinguística sobre as variedades da língua, e o grande espaço que o material didático ocupa nas aulas de português, este estudo objetiva investigar como é realizado o trabalho com variação linguística em uma coleção de livros didáticos de português para os anos finais do Ensino Fundamental ( $6^{\circ}$ ao $9^{\circ}$ ano), aprovada pelo Programa Nacional do Livro Didático (PNLD-2014). O estudo é baseado nos pressupostos teóricos de vários trabalhos, sobretudo nos de Fernández (1998), Bagno (2002; 2007) e Possenti (2002); e pauta-se, ainda, nos Parâmetros Curriculares Nacionais do terceiro e quarto ciclos de Língua Portuguesa (BRASIL, 1998).
\end{abstract}

Palavras-chave: Ensino de português. Variação linguística. Livro didático.

\begin{abstract}
Considering the relevance of reflection about the process of didactic transposition, more specifically the contributions brought by sociolinguist studies about language variation, and the widespread usages of textbooks in Portuguese classes, this study aims to investigate how the work with linguistic variations is carried out in a collection of Portuguese textbooks for High School approved by National Program of Textbooks (Programa Nacional do Livro Didático - 2014). The study is theoretically based on several works, mainly on Fernández's (1998), Bagno's (2002; 2007 ) and Possenti's (2002) ones; also on National Curricular Parameters of Portuguese Language (Parâmetros Curriculares Nacionais) (Brasil, 1998).
\end{abstract}

Keywords: Portuguese Teaching. Language Variation. Textbook.

\section{Introdução}

Estudos que consideram a língua como fato social e o uso da linguagem como sendo sócio-historicamente situado começaram a ganhar espaço no âmbito dos locais destinados à pesquisa (no Brasil, sobretudo, nas universidades federais), principalmente a partir da década de 1980. É partindo dessa concepção que a variação linguística passa a ser um dos tópicos de discussão na academia.

Entretanto, apenas no início dos anos 90, sedimentando-se no fim dessa década, é que as contribuições das pesquisas na área da Sociolinguística passaram a trazer subsídios teórico-metodológicos mais diretos para a formação do professor de português e, consequentemente, para suas práticas pedagógicas; momento este, inclusive, em que foram publicados os Parâmetros Curriculares Nacionais (BRASIL, 1998), documento basilar para os docentes, em que são encontradas repercussões das contribuições advindas dos estudos da Ciência da Linguagem e da Educação.

Dessa forma, o trabalho com variedades linguísticas do português não poderia ficar de fora dos materiais didáticos utilizados pelos professores; sobretudo, após o lançamento do Programa Nacional do Livro Didáticos (doravante PNLD) ${ }^{1}$, instituído pelo Ministério da Educação em 1997.

\footnotetext{
* Professora Doutora da Universidade Federal da Paraíba (UFPB) e do Programa de Pós-Graduação em Linguística (PROLING/UFPB). Endereço eletrônico: evangelinab.faria@gmail.com

${ }^{* *}$ Professor Mestre da Universidade Federal Rural de Pernambuco (UFRPE); doutorando pelo PROLING/UFPB. Endereço eletrônico: ewertonavila2@gmail.com

${ }^{1}$ Embora já se tivesse criado, no final dos anos 20, o Instituto Nacional do Livro, foi com a criação do PNLD que a avaliação dos livros didáticos começou a repercutir nas vendas desses materiais. O PNLD, então, "tem como principal objetivo subsidiar o trabalho pedagógico dos professores por meio da distribuição de coleções de livros didáticos aos alunos da educação básica. Após a avaliação das obras, o Ministério da Educação (MEC)
} 
Com base nesse contexto e nos trabalhos com formação de professores de português ao longo dos últimos anos, surgiu a seguinte pergunta: como ocorreu o processo de transposição didática de aspectos teóricos da sociolinguística referentes a variedades linguísticas para os livros didáticos de Português?

O objetivo deste estudo, portanto, é investigar como a temática das variedades da língua está inserida no livro didático de português. Acreditamos que estudos como estes são relevantes por várias razões. Primeiro, porque esses materiais são de uso recorrente dos professores brasileiros que atuam na Educação Básica. Segundo, de acordo com Chevallard (1991), são necessárias mais pesquisas que investiguem a relação entre a academia e a escola, ou seja, que reflitam como é didatizado um saber construído no contexto científico para ser inserido na escola ${ }^{1}$. E terceiro, porque, segundo Bagno, "numa comparação com a produção bibliográfica sobre linguística textual, leitura, escrita, gêneros textuais, análise do discurso, etc., a gente logo percebe que são poucos os títulos que abordam especificamente a variação" (2007, p. 29), principalmente quando nos voltamos para as práticas da sala de aula.

A fim de analisarmos o livro didático (5), é necessário antes destacar as bases teóricas que fundamentam o artigo, tanto do ponto de vista de uma concepção de língua(gem), aqui baseada nos pressupostos da Sociolinguística (2), como no que se refere à aplicabilidade desses conceitos na sala de aula (3). Em seguida (4), são traçados os percursos metodológicos do estudo, em que explicamos as escolhas realizadas (tipo de pesquisa e corpus, por exemplo). Por fim, tecemos algumas considerações finais (6).

\section{Variedade linguística: pelo caráter social da linguagem}

A sociolinguística é a vertente da linguística em que linguagem e sociedade são vistas de forma inseparáveis. Sabemos que esta relação é bastante evidente, mas essa não foi a visão de estudiosos da linguagem que viveram em contextos bastante distintos dos atuais. Segundo Alkmim (2005), no século XIX, por exemplo, a conjuntura científica positivista da época levou muitos pesquisadores a colocarem os estudos da linguagem no plano das ciências naturais, sendo, então, uma abordagem mais social não contemplada.

No início do século XX, embora Saussure admitisse que a língua fosse um fato social, privilegiou o caráter estrutural do fenômeno linguístico. Por outro lado, destaca Alkmim, "a partir dos anos 1930, encontramos linguistas cujas obras são referências obrigatórias, quando se trata de pensar a questão do social no campo dos estudos linguísticos" (2005, p. 24). Dentre eles, cita: Antoine Meillet, Mikhail Bakhtin, Marcel Cohen, Émile Benveniste e Roman Jakobson.

Apesar da contribuição desses estudiosos iniciar-se por volta de 1930, o termo Sociolinguística só foi cunhado na década de 60, em congresso organizado por William Bright, realizado na Universidade da Califórnia, em Los Angeles, em 1964. No evento, estavam presentes, conforme afirmam Bachman et al, "herdeiros de tradições antigas como a da antropologia linguística - caso de Hymes - ou da dialectologia social - como Labov" (1974 apud ALKMIM, 2005, p. 29).

\footnotetext{
publica o Guia de Livros Didáticos com resenhas das coleções consideradas aprovadas. O guia é encaminhado às escolas, que escolhem, entre os títulos disponíveis, aqueles que melhor atendem ao seu projeto político pedagógico". Disponível em <http://portal.mec.gov.br/index.php?Itemid=668id=12391option=com_contentview=article>.

${ }^{1}$ Embora de 1991 até hoje pesquisas sobre transposição didática venham sendo realizadas como, por exemplo, estudos desenvolvidos por membros do Centro de Estudos em Educação e Linguagem da Universidade Federal de Pernambuco, trabalhos desta natureza ainda se fazem necessários.
} 
Como se pode observar, dois aspectos relevantes podem ser destacados: a Sociolinguística já nasce com caráter interdisciplinar; e seus estudos iniciais levaram à contraposição, então, da visão imanente da língua, conforme proposto por Chomsky.

Os trabalhos de Labov foram de grande relevância para este ramo da ciência, sobretudo no que se refere ao seu foco de estudo: variação e mudança linguística. $O$ pesquisador postulou que a variação é inerente às línguas naturais e está relacionada a fatores extralinguísticos. Para estudar a fala espontânea, desenvolveu aparato teórico-metodológico que utiliza dados estatísticos em ocorrências distintas, considerando aspectos como classe social, escolaridade, ocupação, idade, sexo, origem étnica, entre outros.

Uma ilustração desta questão pode ser vista no estudo feito por Labov (2008) que resultou no texto "A estratificação social do (r) nas lojas de departamentos na cidade de Nova York", publicado no início da década de 70 no livro Padrões Sociolinguísticos. No estudo, o autor investigou como falavam funcionários de três lojas com diferentes prestígios sociais (uma de luxo, outra mediana e outra mais popular). Os resultados apresentam a estratificação social do " $\mathrm{r}$ " conforme uma série de variáveis como, por exemplo, os fatores econômicos, o sexo, a idade, dentre outros.

A partir dessa breve discussão sobre o caráter social da linguagem, com base em contribuições da Sociolinguística, é que destacamos a concepção de língua ora adotada: "sistema intrinsecamente heterogêneo, em que se entrecruzam e são correlacionáveis fatores intra e extralinguísticos, ou seja, fatores estruturais e fatores sociais (como classe, sexo, idade, etnia, escolaridade, estilo)" (MATOS E SILVA, 2004, p. 299).

É à luz dessa perspectiva que será analisada a coleção de livro didático de português, antes, faz-se necessário que outras concepções teóricas que norteiam este estudo sejam destacadas.

Comecemos, então, pelo conceito de variedade que não é tão simples quanto parece, sendo, por isso mesmo, discutido ao longo do tempo por alguns estudiosos. Para Hudson (1981), por exemplo, a variedade linguística é uma manifestação da linguagem formada por um conjunto de elementos de similar distribuição social. Conforme essa concepção, estariam relacionados, logo, termos como dialeto, estilo, registro ou qualquer uso linguístico, de modo geral, em que se possa observar valor social (FERNÁNDEZ, 1998, p. 85). Como se percebe, não se deixa de considerar o caráter essencialmente social da língua, embora esta seja uma concepção ampla que envolve vários fenômenos relacionados aos usos linguísticos.

De acordo com Fernández, Ferguson conceituou variedade de uma forma mais concreta do que o proposto por Hudson. Segundo Ferguson (1971):

Uma variedade é um conjunto de padrões linguísticos o suficientemente homogêneo que pode ser analisado mediante técnicas linguísticas de descrição sincrônica; tal conjunto estaria formado por um repertório de elementos suficientemente extenso e poderia operar em todos os contextos de comunicação². (FERGUSON, 1971 apud FERNÁNDEZ, 1998, p. 86, tradução nossa)

Essa concepção, para Fernández, seria mais clara uma vez que termos como língua e dialeto seriam considerados variedades, mas estilo e registro, por exemplo, seriam manifestações distintas de uma mesma variedade linguística.

Baseamo-nos nos pressupostos de Fernández (1998) em relação ao uso do termo variedade, uma vez que consideramos, corroborando o autor, que as variedades (destacamos o

\footnotetext{
${ }^{2}$ Una variedad es un conjunto de patrones lingüísticos lo suficientemente homogéneo como para ser analizado mediante técnicas lingüísticas de descripción sincrónica; tal conjunto estaría formado por un repertorio de elementos suficientemente extenso y podría operar en todos los contextos normales de comunicación.
} 
uso do plural) da língua relacionam a associação de elementos linguísticos a fatores externos (grupos sociais, contextos situacionais, etc.).

Assim como o termo variedade, os termos língua e dialeto também foram conceituados por vários estudiosos (Ascoli, final do século XIX; Alvar, 1961, 1979). Há inclusive aqueles, como Paris e Meyer, que afirmaram que dialetos não existem, sobretudo do ponto de vista linguístico (cf. FERNÁNDEZ, 1998, p.86-87).

Fernández (1998) afirma fazer sentido refletir sobre dialeto, principalmente se considerarmos: o fato da perspectiva sociolinguística estar atrelada à natureza extralinguística; e que falantes podem analisar sua variedade diferente de outras, inclusive, atribuindo-a valores.

Para Alvar, os conceitos de língua, dialeto e fala estão dispostos em níveis: enquanto os falantes considerariam o uso da língua como marca de maior prestígio em relação ao dialeto e à fala; a fala seria uma realidade de uso mais concreta do que a língua. Para tornar mais clara esta discussão, citamos Alvar (1982), conceituando, respectivamente, língua, dialeto e fala:

\section{Língua}

O sistema linguístico de que se vale uma comunidade de fala e que se caracteriza por estar fortemente diferenciado, por possuir um alto grau de nivelação, por ser veículo de uma importante tradição literária e, em ocasiões, por haver se imposto a sistemas linguísticos da mesma origem.

\section{Dialeto}

Sistema de signos depreendido de uma língua comum, viva ou desaparecida, normalmente com uma concreta delimitação geográfica, mas sem uma forte diferenciação frente a outros de origem comum. De modo secundário, podem se chamar dialetos as estruturas linguísticas, simultâneas a outras, que não alcançam a categoria de língua.

$\underline{\text { Fala }}$

Fala regional são as particularidades expressivas próprias de uma região determinada, quando carecem da coerência que tem um dialeto ${ }^{3}$. (ALVAR, 1982 apud FERNÁNDEZ, 1998, p.88, tradução nossa)

Destacamos que esses conceitos não são fáceis de serem colocados em prática, em outras palavras, para categorizar uma variedade em língua, dialeto ou fala, nessa perspectiva, é necessário fazer investigações que busquem as isoglossas, percurso histórico e atitudes linguísticas. Como estas questões não são foco deste estudo, não as exploraremos. Entretanto, ressaltamos o que afirma Fernández ao mencionar que, quando nos referimos a dialeto e à língua, devemos considerar que se tratam de modalidades concretas de uso linguístico que não devem ser desprestigiadas.

Em relação ao termo estilo, embasamo-nos em Labov (2008). Para Labov, os estilos estariam dispostos em uma escala que permite variação no grau de formalidade. Dentre alguns

\footnotetext{
${ }^{3}$ Lengua - El sistema lingüístico del que se vale una comunidad hablante y que se caracteriza por estar fuertemente diferenciado, por poseer un alto grado de nivelación, por ser vehículo de una importante tradición literaria y, en ocasiones, por haberse impuesto a sistemas lingüísticos de su mismo origen.

Dialecto - Sistema de signos desgajado de una lengua común, viva o desaparecida, normalmente con una concreta delimitación geográfica, pero sin una fuerte diferenciación frente a otros de origen común. De modo secundario, pueden llamarse dialectos las estructuras lingüísticas, simultáneas a otras, que no alcanzan la categoría de lengua.

Habla - Habla regional son las peculiaridades expresivas propias de una región determinada, cuando carezcan de la coherencia que tiene el dialecto.
} 
estilos elencados pelo pesquisador, temos o vernáculo, fala pouco monitorada e informal, e o formal, adquirido através, principalmente, da leitura de textos.

Os estilos seriam, pois, um conjunto de possibilidades linguísticas que, muitas vezes, não é fácil de ser medido já que os limites entre um e outro podem ser tênues. Corroborando Labov, Fernández (1998) destaca que:

Falamos de um parâmetro gradual que representa o nível de formalidade do discurso, considerando a formalidade como a conduta guiada por uns critérios de máximo respeito às normas sociolinguísticas e ao prestígio ${ }^{4}$. (FERNÁNDEZ, 1998, p. 96, tradução nossa)

Esta breve discussão sobre estilo faz-se necessária neste estudo uma vez que as variedades estilísticas estão muitas vezes relacionadas às variedades sociolinguísticas. A escolha do estilo realizada pelo usuário estará relacionada a fatores extralinguísticos e, portanto, sociais, de forma mais ampla, e, sobretudo, situacionais, de forma mais específica (qual a ocupação dos envolvidos na interlocução, qual a relação entre interlocutores, qual suas posições em uma escala de estratificação social, qual o objetivo do encontro, em que meio é realizado etc.).

Explicitadas estas concepções teóricas, é possível, então, discutir sobre como elas repercutem, ainda no plano teórico, em reflexões associadas ao ensino de português enquanto língua materna no Brasil. Logo, no tópico seguinte, é considerado como as contribuições de uma área como a Sociolinguística - sobretudo sobre a temática da variação linguística podem repercutir no processo de formação educacional do cidadão.

\section{Variação e ensino: por uma educação linguística}

Iniciamos este tópico com duas perguntas que têm estado presentes em várias publicações sobre o ensino de língua nas últimas décadas (GERALDI, 2002; BAGNO, 2002; POSSENTI, 2002; entre outras), nos cursos de formação (inicial e continuada) de professores e nos documentos oficiais que regem a prática docente (BRASIL, 1998, 2000): Quais os objetivos do ensino-aprendizagem do Português como língua materna enquanto disciplina curricular na Educação Básica? Que usuário de língua queremos formar?

A concepção de língua anteriormente apresentada direciona as práticas pedagógicas para um sentido em que os usuários da língua não são desconsiderados. Nessa perspectiva, então, o ensino da língua portuguesa não deve se restringir à memorização de aspectos estruturais e passa a ter como foco a reflexão sobre questões linguístico-discursivas, o que contempla os fatores extralinguísticos, essenciais para o processo de interação.

Nesse caso, dentre os objetivos do Português, enquanto disciplina escolarizada, teríamos a possibilidade de desenvolver habilidades e competências na área de linguagem de modo a contribuir para a educação linguística do usuário da língua. Bagno (2002) é um dos que defendem essa educação na escola de forma reflexiva e sistemática. Para o autor:

(...) o ensino de língua na escola deveria propiciar condições para o desenvolvimento pleno de uma educação linguística - conceito que difere em muito da prática tradicional de inculcação de uma suposta "norma culta" e de uma metalinguagem tradicional de análise da gramática. (BAGNO, 2002, p. 17, grifo do autor).

\footnotetext{
${ }^{4}$ Hablamos de un parámetro gradual que representa el nivel de formalidad del discurso, considerando la formalidad como la conducta guiada por unos criterios de máximo respeto hacia las normas sociolingüísticas y hacia lo prestigioso.
} 
A diversidade das práticas linguageiras, logo, deve ser foco das reflexões da aula de Português. O conhecimento gramatical, que é tão importante, passa a ser associado aos processos de construção dos sentidos dos textos lidos, escritos, ouvidos e falados. Nesse contexto, variedades diferentes da língua padrão ganham espaço nos momentos de reflexão sobre a língua.

Esse tratamento dado à linguagem possibilitaria o desenvolvimento de uma educação linguística. Em síntese, Bagno (2002) destaca a importância, então, de práticas que contemplem:

(i) o desenvolvimento ininterrupto das habilidades de ler, escrever, falar e escutar;

(ii) o conhecimento e reconhecimento da realidade intrinsecamente múltipla, variável e heterogênea da língua, realidade sujeita aos influxos das ideologias e dos juízos de valor;

(iii) a constituição de um conhecimento sistemático sobre a língua, tomada como objeto de análise, reflexão e investigação (BAGNO, 2002, p. 18).

Possenti (2002), em capítulo publicado no livro Linguística da Norma, corrobora a ideia de prezar por uma educação linguística. Mas para isso, o autor afirma que são necessárias algumas considerações que acredita ser essenciais e que deveria haver um programa mínimo, ou seja, aspectos a serem considerados por todas as redes de ensino, por todas as escolas, por todos os professores. Dentre elas, é mencionado a não lamentação da realidade, ou seja, "não adianta lamentar que os alunos falem como falam e, portanto, que seu saber linguístico esteja mais ou menos distanciado do padrão que se quer atingir..." (POSSENTI, 2002, p. 320).

Considerar as características linguísticas do aluno é considerá-lo enquanto sujeito e esse é um ponto de partida relevante para os momentos de planejamentos e estabelecimentos de objetivos. De acordo com Soares (2002), é necessário que se reflita sobre momentos sóciohistóricos para entender que perspectiva de ensino de Português será escolhida, atrelada sempre a uma concepção de língua(gem), e isso inclui fatores externos como:

Que grupos sociais têm acesso à escola? A quem se ensina a língua? Que expectativas, interesses, objetivos, têm esses grupos e a sociedade como um todo em relação à escola e ao que se deve ensinar e aprender nela, a respeito da língua materna? Em que regime político se insere a escola e o ensino de língua? Em que estrutura de sistema educacional? (SOARES, 2002, p. 175176).

Um projeto de ensino de língua resulta de um projeto de sociedade, e a escola tem se preocupado bastante com a construção de uma unidade em que há “"distribuição' do mesmo saber entre sujeitos sociais diferentes e desiguais" (GERALDI, 2011, p. 8).

Além dos fatores externos citados por Soares (2002), a autora acrescenta, ainda, fatores internos, como "em que estágio de desenvolvimento encontram-se os conhecimentos sobre a língua?" (SOARES, 2002, p. 176). Em relação a essa questão, conforme discutido em tópico anterior, a ciência da linguagem, em geral, e a Sociolinguística, em particular, deram e dão contribuições importantes à formação inicial e continuada dos professores de português.

É a partir desses conhecimentos que é possível que a escola conheça seus alunos com suas características efetivas de seus usos linguísticos. Retornando a Possenti (2002), essa seria uma tarefa presente em um programa mínimo para a educação linguística. Para o autor, entretanto: 
Não se trata de descrever exaustivamente um dialeto, de fazer dele uma gramática completa, o que seria uma tarefa infindável. Trata-se de descrever os traços mais salientes da fonologia e/ou da pronúncia local (por exemplo, se há variações como "bicicleta / bicicreta", "alho / aio / ai", "menino / meninu", "louro / loro", "feito "feitcho" etc.), da morfologia (qual é a flexão verbal realmente empregada, por exemplo) e de alguns aspectos da sintaxe (há ou não variações como "os meninos / os menino", "viu-me / me viu / viu eu" etc.) e de léxico (em que medida regionalismos ou gírias caracterizam de fato - insisto nisso: de fato - a fala da região) (POSSENTI, 2002, p. 320$321)$.

Esse conhecimento permite à escola saber qual é o ponto de partida. Como mencionado anteriormente, permite que o docente reconheça quem são seus alunos, a que comunidade pertencem, quais marcas estão presentes em sua fala.

Os documentos oficiais também direcionam o professor para uma formação holística do sujeito. $\mathrm{O}$ usuário da língua não apenas a compreende do ponto de vista estrutural, mas, sobretudo, em relação a suas possibilidades de uso e de adequação linguística. Dentre os objetivos gerais de Língua Portuguesa, por exemplo, constam nos Parâmetros Curriculares Nacionais (anos finais do Ensino Fundamental):

- analisar criticamente os diferentes discursos, inclusive o próprio, desenvolvendo a capacidade de avaliação dos textos:

○ identificando e repensando juízos de valor tanto socioideológicos (preconceituosos ou não) quanto históricoculturais (inclusive estéticos) associados à linguagem e à língua;

- reafirmando sua identidade pessoal e social; (...)

- conhecer e valorizar as diferentes variedades do Português, procurando combater o preconceito linguístico;

- reconhecer e valorizar a linguagem de seu grupo social como instrumento adequado e eficiente na comunicação cotidiana, na elaboração artística e mesmo nas interações com pessoas de outros grupos sociais que se expressem por meio de outras variedades; (BRASIL, 1998, p. 33).

Esses objetivos estão diretamente relacionados ao aluno que a escola precisa formar: um cidadão crítico e ativo que utiliza a língua para interagir de forma adequada às mais variadas situações. Sujeito capaz de observar, construir hipóteses e analisar os usos da língua, essencialmente heterogênea, com a qual podemos apreender a realidade e nela intervir.

De acordo com Bagno, "numa sociedade, como a brasileira, tradicionalmente excludente e discriminadora, é fundamental que a escola possibilite a seus aprendizes o acesso ao espectro mais amplo possível de modos de expressão" (BAGNO, 2010). Desse modo, é possível fazer com que a educação linguística contribua para que os sujeitos compreendam o que não foi explicitamente dito, atente para os processos discriminatórios (tanto na posição de agente como paciente), e entendam que a linguagem pode refletir juízos de valor.

É essa formação escolar sobre a língua que permitirá, conforme Bagno (2010), que se compreenda que “onde alguns falam de 'terrorismo' outros preferem falar de 'revolução"”; “o que o governo americano chamou de 'Guerra do Iraque' muitos analistas classificam simplesmente de "invasão"'.

Nesse contexto, os profissionais da educação - professores, autores de livros didáticos, etc. - ocupam papel fundamental, uma vez que além de conhecer seu aluno (isso 
para os docentes), como propõe Possenti, é necessário, ainda, que saibam lidar com suas variedades linguísticas e, em determinados momentos, utilizá-las como objeto de ensino.

O processo de formação inicial e continuado desses profissionais, portanto, é que permitirá a construção de concepções teórico-metodológicas sólidas sobre variados aspectos da língua e sobre seu ensino. Segundo Bortoni-Ricardo (2004), os educadores brasileiros, com destaque para os linguistas, têm contemplado as contribuições sociolinguísticas em suas práticas docentes. Para a autora, temos muitas vezes "uma pedagogia que é culturalmente sensível aos saberes dos educandos" (BORTONI-RICARDO, 2004, p. 38); acrescenta também que esta pedagogia "está atenta às diferenças entre a cultura que eles [alunos] representam e a da escola. E mostra ao professor como encontrar formas efetivas de conscientizar os educandos sobre as diferenças" (BORTONI-RICARDO, 2004, p. 38).

O fato é que, apesar das inúmeras contribuições advindas de pesquisas (BAGNO, 2007, 2010; BORTONI-RICARDO, 2004; dentre outras), muitos professores e autores de coleções de livros didáticos possuem dificuldades em lidar e trabalhar com variação. Conforme destaca Bagno (2007):

A gente percebe, em muitas obras, uma vontade sincera dos autores de combater o preconceito linguístico e de valorizar a multiplicidade linguística do português brasileiro. Mas a falta de uma base teórica consistente [...] prejudica muito o trabalho que se faz nessas obras em tornos dos fenômenos de variação e mudança (BAGNO, 2007, p. 119).

É por isso que ainda se fazem necessários mais estudos sobre a temática, além, claro, de maior investimento por parte dos governos e dos próprios professores em formação continuada.

\section{Metodologia}

A metodologia de uma pesquisa é definida a partir do objeto de estudo. É ele que vai indicar o caminho a seguir, os instrumentos a serem utilizados na coleta de dados, a perspectiva a partir da qual esses dados serão analisados etc. E é pela especificidade do nosso objeto - o livro didático de português - que optamos pela pesquisa documental de cunho qualitativo.

Os materiais didáticos, especialmente o livro didático - constituem-se como suporte às práticas pedagógicas, sobretudo no contexto atual em que professores possuem grandes jornadas de trabalho. Segundo Sacristán (2000):

As condições atuais da realidade impõem aos professores acudir a préelaborações do currículo para seu ensino, que se podem achar na tradição profissional acumulada e nos agentes externos que lhes ofereçam o currículo elaborado. A debilidade da profissionalização dos professores e as condições nas quais desenvolvem seu trabalho fazem com que os meios elaboradores do currículo sejam como dispositivos intermediários, essenciais e indispensáveis no atual sistema escolar. Esta é a função capital que os meios didáticos cumprem, mas sobretudo os guias didáticos e os livros-texto, que são os autênticos responsáveis da aproximação das prescrições curriculares aos professores (SACRISTÁN, 2000, p. 149, grifo do autor).

Embora muitas críticas sejam feitas aos materiais didáticos e aos seus usos (mais àqueles do que a estes), incluindo opiniões aparentemente radicais contra a adoção de livros 
dessa natureza (cf. GERALDI, 1987), o fato é que eles estão muito presentes nas salas de aula do país, contribuindo para a ampliação do grau de letramento dos alunos e, por que não, dos professores - muitas vezes por ser praticamente o único meio de acesso à cultura letrada (SACRISTÁN, 2000).

É em função dessa presença que estudos que relacionam aspectos teóricometodológicos de uma área de conhecimento ao tratamento didático presente em textos do saber, como os livros didáticos, são bastante relevantes. Daí a importância deste estudo: analisar como esse material tão presente na vida dos estudantes é teórico-metodologicamente pensado, organizado, no que se refere ao trato das variedades linguísticas do português.

Justificada a escolha do objeto de estudo, ressaltamos que, para realização desta pesquisa de natureza qualitativa, analisamos apenas uma coleção de livro didático de português destinada a alunos dos anos finais do Ensino Fundamental ( $6^{\circ}$ ao $9^{\circ}$ ano). A escolha da coleção e desse segmento se deu por duas razões: primeiro porque foram foco do Programa Nacional do Livro Didático (PNLD) deste ano e, segundo, porque a coleção foi aprovada por atender a princípios e critérios de avaliação presentes no Edital de Convocação para o processo de inscrição e avaliação de coleções didáticas para PNLD 2014, os quais contemplam, para o componente curricular Língua Portuguesa:

2.3. o desenvolvimento de atitudes, competências e habilidades envolvidas na compreensão da variação linguística e no convívio democrático com a diversidade dialetal, de forma a evitar o preconceito e valorizar as diferentes possibilidades de expressão linguística (BRASIL, 2011, p. 69).

Vale destacar que foram, ao todo, 57 coleções aprovadas na referida edição do PNLD; entretanto, selecionamos aleatoriamente uma das que tivessem sido submetidas pela primeira vez a essa seleção e, portanto, se configurasse como um material didático novo no mercado. Nesses termos, escolhemos a coleção intitulada "Singular e Plural - Leitura, Produção e Estudos da Linguagem", de autoria de Laura de Figueiredo, Marisa Balthasar e Shirley Goulart, pertencente à Editora Moderna (que teve essa coleção como a única obra de Língua Portuguesa aprovada no PNLD 2014).

De acordo com o objetivo deste estudo, anteriormente mencionado, o nosso foco de análise recai sobre a forma como a coleção selecionada realiza o trabalho didático sobre variedades linguísticas. Ressaltamos que não era objetivo investigar, então, se a temática estava presente, uma vez que a coleção foi aprovada no PNLD e, conforme os critérios de avaliação e aprovação de livro didático constantes desse edital, as obras selecionadas devem valorizar e trabalhar a variação linguística.

\section{Análise dos dados}

A coleção analisada apresenta os momentos de reflexão sobre variedades linguísticas em seções determinadas, uma vez que embora aborda a temática de forma sistemática no livro do $6^{\circ}$ ano, no Caderno de Estudos de Língua e Linguagem ${ }^{5}$ (Capítulo 2 da Unidade 1). Apesar de contemplar a questão como um conteúdo que é foco central dos estudos da unidade em que está inserida, não apresenta oportunidades de reflexão e debate sobre a temática ao longo de toda obra.

\footnotetext{
${ }^{5}$ Além do Caderno de Estudos de Língua e Linguagem, os livros da coleção apresentam o Caderno de Leitura e Produção e o Caderno de Práticas de Literatura.
} 
Não acreditamos que essa estratégia seja inválida. Entretanto, destacamos que a discussão não deve ser esquecida em outros momentos de uma coleção de livro didático de português. De acordo com Bagno (2007),

É incoerente pedir respeito e tolerância diante da variação linguística e dizer, nos exercícios de gramática, que usar o pronome ELE como objeto direto é um "erro", ou que o pronome VOCÊ é apenas "forma de tratamento", ou que é "proibido" iniciar frases com pronomes oblíquos, ou que não se pode dizer EU CUSTO A CRER mas somente CUSTA-ME CRER.. (BAGNO, 2007, p. 135).

Na coleção analisada, o Caderno de estudos de Língua e Linguagem está dividido em três unidades: Língua e linguagem, Língua e gramática normativa, Ortografia e pontuação. Nas duas últimas encontramos exercícios que não contemplam a variação. Não que a discussão precise estar sempre presente, mas não encontramos, por exemplo, atividades sobre a norma-padrão que contemplem, de algum modo, o fato de mesmo a variável de prestígio sofrer variação e ser distinta do que está pontuado em algumas gramáticas mais tradicionais (ex.: algumas colocações pronominais, regências, etc.).

O capítulo 2 está dividido em duas partes. A primeira intitulada "Língua e mudança" / "Língua e variação" e a segunda, "O uso da língua e as situações de comunicação". Essa última contempla questões relacionadas ao domínio discursivo, à escolha de registro e à relação entre a modalidade oral e a escrita da língua. Embora esta parte seja também importante para a formação do aluno, como nosso objetivo é analisar o trabalho com a variação linguística, enfocaremos apenas a primeira parte.

Nessa seção, o aluno é levado a refletir sobre as mudanças pelas quais a língua portuguesa vem passando ao longo dos anos. A variação histórica é cerne da discussão através de trechos de anúncios retirados de uma edição de jornal datada de 1821, de uma publicidade de 1935 e de um poema em galego-português (p. 196-197). Após as questões de interpretação desses três textos, que incitam o aluno a observar as diferenças na língua ao compará-la aos dias atuais, as autoras sistematizam a discussão sobre variação histórica com uma figura explicativa (Fig.1), conforme podemos observar a seguir:

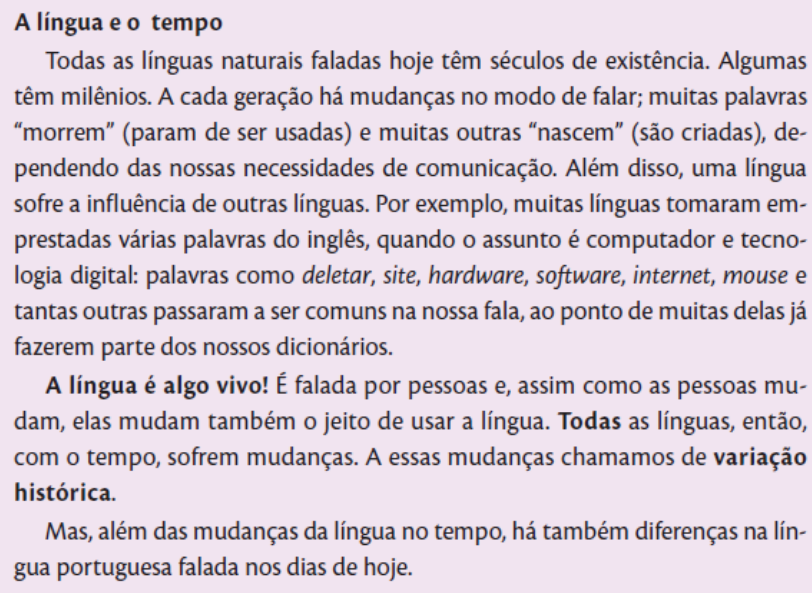

Figura 1 - A língua e o tempo

Fonte: Figueiredo; Balthasar; Goulart (2002, p. 198)

A reflexão sobre mudança linguística foi escolhida pelas autoras para iniciar a discussão sobre variação. Estratégia válida uma vez que é sabido que a mudança na língua não ocorre apenas do ponto de vista diacrônico. Para Tarallo, "inicia-se o processo de 
investigação no momento presente; volta-se ao passado para o devido encaixamento histórico das variantes, retornando-se, a seguir, ao presente para o fechamento do ciclo de análise" (2005, p. 64).

Como se pode perceber, a mudança linguística é um fato complexo, em que a relação diacronia-sincronia se mostra possível na interpretação do fenômeno, na busca da compreensão de uma variação ou mudança em fase inicial de implementação ou em fase de conclusão. É importante ressaltar, ainda, que se entende que variação não implica mudança, mas mudança implica sempre variação (TARALLO, 2005).

No exemplo citado do material didático, destacamos, dentre outros fragmentos, como boa oportunidade de debate em sala de aula, o relacionado à 'morte' e ao 'nascimento' das palavras, a influência entre línguas, e o fato de que 'todas' as línguas passam por mudanças e variam.

No final do capítulo (Fig.2), encontramos a seguinte atividade:

3. Observe as palavras destacadas nas seguintes manchetes. Elas são prova de que a língua portuguesa continua se transformando.

I. Blogueiro é preso acusado de extorquir políticos em Salvador.

II. Brasileiro é um dos mais retuitados do mundo durante Oscar.

III. Gabriela Duarte: ciumenta, chocólatra e não leva desaforo para casa.

IV. Avril Lavigne posta foto fazendo nova tatuagem.

a) Qual é o significado de cada uma das palavras destacadas?

b) Como você imagina que elas surgiram na língua portuguesa?

c) O verbo postar existe na língua portuguesa há muito tempo, mas antes era normalmente usado em frases como: "Vou até o correio postar algumas cartas". O que mudou entre o uso antigo e o uso atual, exemplificado na última manchete lida?

Figura 2 - A língua renova-se

Fonte: Figueiredo; Balthasar; Goulart (2002, p. 208-209)

Nela podemos observar que o aluno é levado a entender que mudança e variação linguística são fenômenos que não estão relacionados apenas a fatos passados, mas que acontecem a todo o momento, inclusive no momento em que ele está inserido. A reflexão proposta a partir dos usos da palavra "postar" é um exemplo disso. O aluno, a partir da questão (letra c) é levado a refletir sobre os contextos de uso associados às práticas linguageiras.

Em momento posterior à discussão sobre variação histórica (Fig.3), as autoras selecionam uma tirinha (Tiras do Mutum - Diogo Sales) que traz dois personagens, brasileiros, mas de cidades diferentes conversando sobre o quão estranho é o sotaque do outro. Nesse caso, a pronúncia das palavras é o elemento a ser analisado.

2. Agora, leia a tira e responda às questôes.

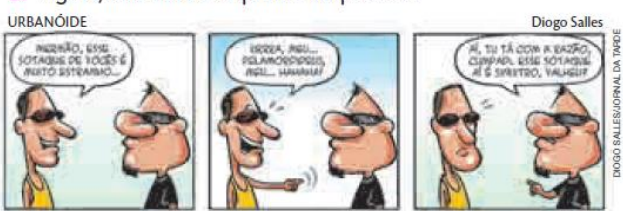

a) Urbanóide, a personagem de barbicha, é um paulistano. A outra personagem também é paulistana? Explique com base, especialmente, na fala do primeiro quadrinho.

b) Observe a fala do Urbanóide no último quadrinho. O jeito de falar e o sotaque - que fica marcado na escrita das palavras sinixtro e valheu - é de paulistano? Explique.

c) Analise as palavras estranho e sinixtro. Qual está representando o sotaque paulistano e qual representa o outro sotaque?

d) Afinal, o que aconteceu nessa tira?

Figura 3 - Sotaques

Fonte: Figueiredo; Balthasar; Goulart (2002, p. 199) 
A atividade mostra que há uma preocupação com a gradação em que os tópicos vão ser apresentados. Isso não significa que questões de acentos diferentes sejam simples e não possam ser problematizadas. Entretanto, a um olhar menos preciso, a expressão "língua e variação", título do tópico do capítulo analisado, pode remeter a variações dessa natureza.

É considerando essa gradação, inclusive, que acreditamos que o momento não tenha sido aproveitado para uma discussão mais aprofundada sobre estereótipos, já que a tirinha escolhida pelas autoras e o comentário intitulado "Pronúncia diferente dos sons das palavras" [p. 199] poderia suscitar. Nas páginas que seguem essa atividade é que encontraremos reflexões sobre identidade e preconceito linguísticos.

Em tira seguinte - Tapejara, de Paulo Louzada - será a vez do léxico. Para ajudar na compreensão textual e na resolução das questões propostas, é acrescido um excerto de um dicionário Gaúcho (Alberto J. de Oliveira). Nessa atividade (Fig.4), é possível encontrar perguntas que estimulam do aluno um olhar para o fenômeno linguístico como podemos observar na questão três:
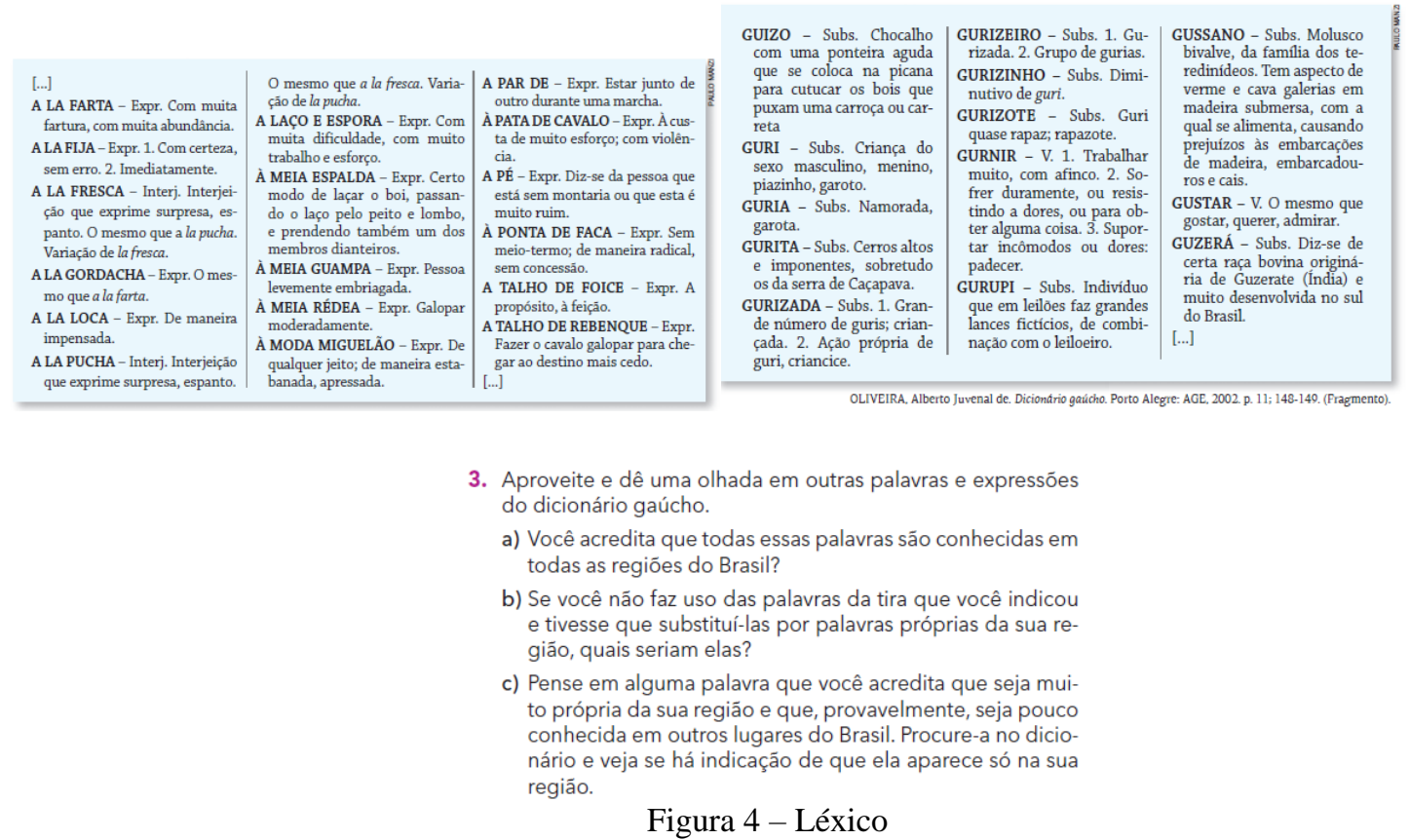

Fonte: Figueiredo; Balthasar; Goulart (2002, p.203-204)

A questão oportuniza ao aluno refletir sobre característica do português utilizado no Rio Grande do Sul e locais adjacentes, além de chamar a atenção para o fato de que a região do estudante também possui particularidades linguísticas.

Por outro lado, a primeira questão, citada a seguir, torna a atividade mais longa e não parece contribuir para práticas reflexivas: "Copie no caderno palavras ou expressões típicas das pessoas dessa região [Sul do país]. Caso não saiba quais seriam, selecione as que você não conhece" (p. 203).

As variedades do campo x cidade também estão presentes, como pode ser observado na atividade seguinte (Fig.5): 


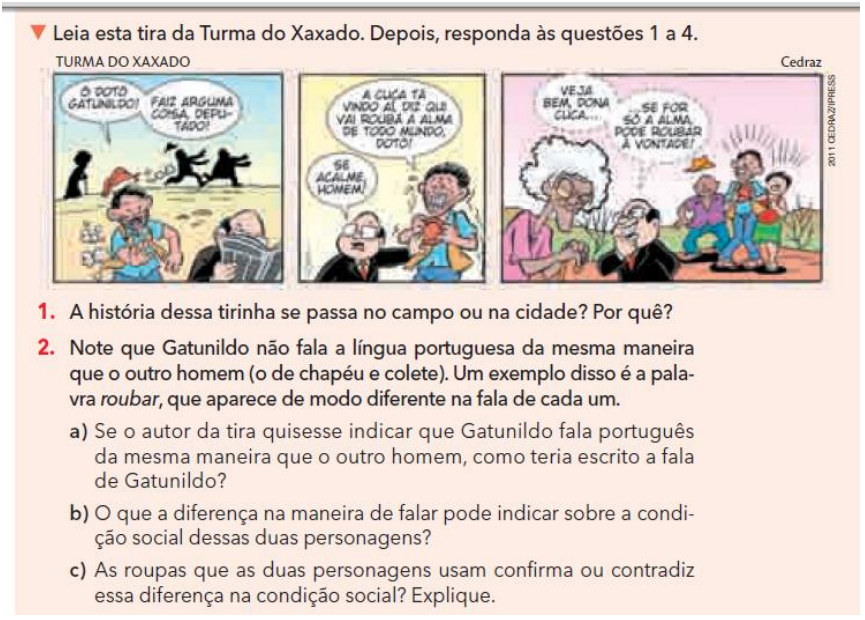

Figura 5 - Campo-cidade

Fonte: Figueiredo; Balthasar; Goulart (2002, p. 209)

Nessa atividade, uma preocupação nossa está relacionada à escolha das marcas de variedade. Isso porque o enunciado da questão dois chama atenção para o uso do "roubá" e "roubar". Entretanto, sabemos que nas variedades de prestígio também se pode encontrar o uso de "roubá". De acordo com Bagno, "é um traço linguístico de todas as variedades linguísticas brasileiras, independente de região ou classe do falante, a eliminação do $\mathrm{R}$ final dos infinitivos..." (BAGNO, 2007, p. 121). A questão central, então, é que não podemos correr o risco de o aluno pensar que as variedades da língua estão relacionadas apenas a falantes do campo, sem escolarização e/ou economicamente desfavorecidos. Ou que os falantes que vivem na cidade usam a língua de forma mais "correta", a norma padrão, e por isso não há variedades.

Apesar disso, o que consideramos de grande relevância, destacamos que é sim importante proporcionar uma discussão sobre variações linguísticas de cunho regional. No processo de educação linguística, nos termos propostos por Bagno (2002) e Possenti (2002), refletir na escola sobre variação regional é essencial, sobretudo por vivemos em um país de tão grandes dimensões territoriais e de tão vasta diversidade linguística.

A variação em função de diferenças socioeconômicas também é abordada, inicialmente, através de outra tira de Mutum (p. 199). Vale destacar que as questões propostas nesse caso articulam diferentes eixos do ensino de língua materna, uma vez que a análise linguística ocorre de maneira integrada à leitura (compreensão leitora). Acreditamos que a articulação entre esses eixos (ou unidades) é que pode contribuir para um ensino voltado para as práticas de usos da língua. Segundo os PCN:

Ainda que a reflexão seja constitutiva da atividade discursiva, no espaço escolar reveste-se de maior importância, pois é na prática de reflexão sobre a língua e a linguagem que pode ser dar a construção de instrumentos que permitirão ao sujeito o desenvolvimento da competência discursiva para falar, escutar, ler e escrever nas diversas situações de interação (BRASIL, 1998, p. 34).

Nas questões sobre a tira (Fig. 6), à medida que o aluno aciona conhecimentos prévios sobre variedades não-padrão, realiza inferências sobre o texto lido, produzindo sentidos e construindo os efeitos pretendidos pelo autor da tira. Isso fica evidenciado nas sete questões da atividade. A questão seguinte é um exemplo disso: 
3. Observe o significado da palavra fartura, usada por Mutum

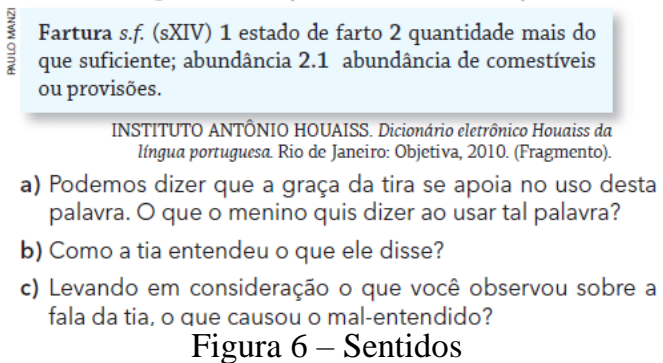

Fonte: Figueiredo; Balthasar; Goulart (2002, p. 200)

O personagem que é o sobrinho fala sobre a 'fartura' de comidas em relação à grande quantidade de comida preparada para pela tia, seguindo o sentido exposto no verbete disponibilizado na questão. Já a tia compreende a palavra a partir de uma variedade nãopadrão em que 'fartura' estaria relaciona a 'fartar', ou seja, 'estar em falta'. Os sentidos opostos da palavra é que geram o efeito cômico pretendido pelo autor da tira.

Outra proposta de atividade da coleção se dá através do estudo do cordel "Ai! Se sesse..." de autoria de Zé da Luz (p. 201). Destacamos, de antemão, que a escolha do texto é importante para oportunizar o contato do aluno com a literatura de caráter popular. Além disso, as autoras acrescentam um pequeno quadro com informações sobre quem foi Zé da Luz e o que representa a sua obra para a sociedade.

Entretanto, diferentemente da atividade proposta para a tira de Mutum (p. 200), a integração entre a reflexão sobre a língua e o processo de leitura não é muito evidente. Isso acontece, infelizmente, quando se está trabalhando com o texto literário, dificultando o processo da vivência literária experienciada pelo aluno no ato de leitura. Segundo Martins, "ao experienciar o texto, por meio da leitura literária, o aluno também deveria ser instrumentalizado, a fim de reconhecer literatura como objeto esteticamente organizado" (2006, p. 84).

Observemos, então, a questão seguinte (Fig.7) como mostra da forma proposta de trabalho com o poema, com enfoque na variação linguística:

4. Agora, observe a construção de uma das frases do texto, comparada à forma como costuma aparecer em livros, jornais e revistas:

Se um dia nois se gostasse

Se um dia nós nos gostássemos

a) $\mathrm{O}$ que ficou diferente entre as duas?

b) Repare em todos os versos do poema em que a construçăo das frases é semelhante.

Se nois dois se empareasse

Se juntim nois dois vivesse

Se juntim nois dois morasse

Se juntim nois dois drumisse

Se juntim nois dois morresse

Se pro céu nois assubisse

[...]

Tarvez que nois dois ficasse

Tarvez que nois dois caísse

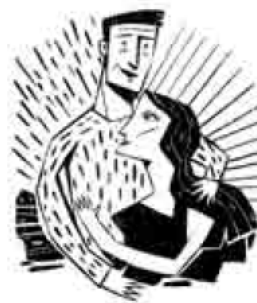

I. Apresente a outra forma de construí-las, como foi mostrado no início da questão. Faça outras modificaçōes que forem necessárias.

II. A construçăo das oraçōes nos versos originais apresenta uma regularidade no uso do pronome nós com o verbo que o acompanha. Qual é?

Figura 7 - Padrão e não padrão

Fonte: Figueiredo; Balthasar; Goulart (2002, p. 202) 
A relação entre a variedade não prestigiada e a norma padrão é abordada com destaque para a estrutura da língua. A pergunta da letra "a", por exemplo, leva o aluno a refletir sobre uma questão de concordância. Em princípio, acreditamos que não há nada de errado com isso. Entretanto, os disparadores das duas próximas questões (I e II da letra "b") também enfocam a estrutura. A proposta de retextualização de "b-I" poderia ser bastante significativa se tivéssemos mais uma terceira questão (b-III), solicitando que o aluno refletisse se a troca alterou o efeito de sentido. Dessa forma, ele poderia concluir que escrever o cordel com a norma padrão faria com que o poema deixasse de ser "Ai! Se sesse...". A escolha de registro e estilo, logo, seria entendida como componente importante para a construção de sentido do texto, considerado como "marcado pela interrelação entre diversos códigos (temáticos, ideológicos, linguísticos e estilísticos)" (MARTINS, 2006, p. 87, grifo nosso). Essa consideração parece não ser levada em conta também nas quatro outras questões sobre o poema. Apesar de a atividade estar na parte do livro dedicada ao estudo da variação linguística, isso não é feito de forma significativa.

As autoras trabalham diferentes textos no decorrer da seção de estudo das variedades linguísticas. No trabalho com alguns deles, não passa despercebida a relação entre língua e identidade, conforme podemos observar na figura seguinte (Fig. 8):

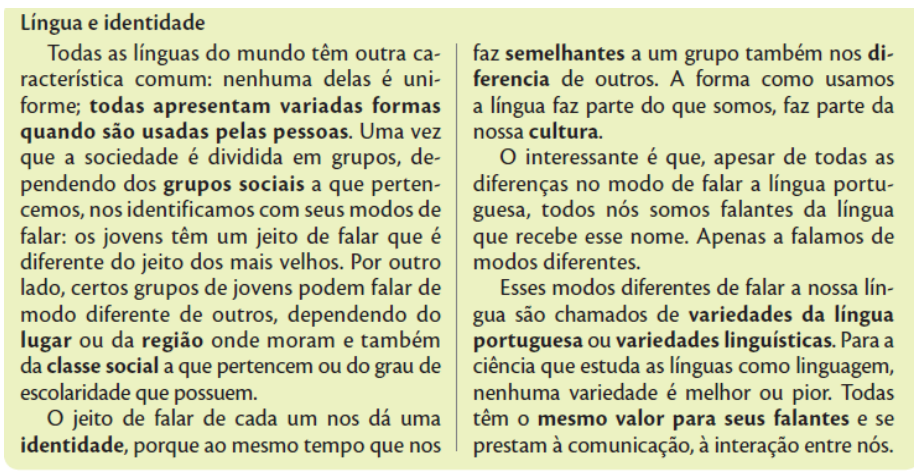

Figura 8 - Identidade

Fonte: Figueiredo; Balthasar; Goulart (2002, p. 205)

Outra questão que também é interessante destacar - como aspecto positivo da obra é o direcionamento ao aluno, deixando-o, de certa forma, próximos das autoras que, apesar de usarem linguagem formal, não enfocam termos da linguística, mas sim o fenômeno linguístico, o que consideramos de maior relevância para os alunos dos anos finais do Ensino Fundamental, público-alvo da Coleção.

O preconceito linguístico também é alvo de estudos já no sexto ano, uma vez que o usuário da língua precisa respeitar as manifestações linguísticas que são diferentes das suas. Segundo os PCN (BRASIL, 1998), é objetivo do Ensino Fundamental, assim como em outros segmentos da Educação Básica, formar cidadãos capazes de respeitar a diversidade. Destacamos isso porque defendemos a ideia, corroborando Romaine (1996), de que a escola, por desempenhar um importante papel na formação do aluno, não pode se restringir aos valores e aos usos linguísticos dominantes. Acreditamos ser relevante criar oportunidades para que os alunos reflitam sobre variedades menos prestigiadas, como as do campo, as do nordeste, as utilizadas por grupos indígenas e as de grupos que vivem em fronteiras (contato linguístico).

Sobre isso, observemos a figura seguinte (Fig. 9): 


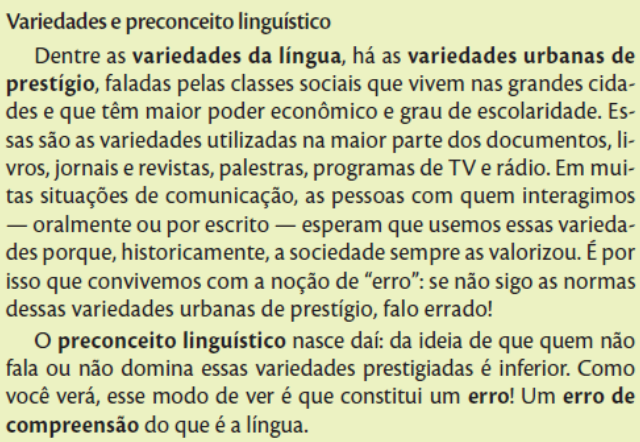

Figura 9 - Preconceito linguístico

Fonte: Figueiredo; Balthasar; Goulart (2002, p. 200)

A explicação do "nascimento" do preconceito é bastante esclarecedora, principalmente porque ela não vem descontextualizada da proposta anterior, que foi a atividade sobre a tira de Mutum que mora na cidade e vai visitar uma tia que vive no sítio longe de sua casa. Se o quadro anterior (Variedades e preconceito linguístico) viesse solto, é provável que os alunos não construíssem o conhecimento da mesma forma. Isso porque, a priori, primeiro realizam a leitura de um texto empírico, que não foi produzido inicialmente para a função de ensinar e aprender; além disso, fazem uma atividade que permite o levantamento de hipóteses e a tirada de conclusões para, enfim, ler o quadro informativo que serve de sistematização das ideias trabalhadas.

Em meio à discussão sobre variedades linguísticas relacionadas a fatores socioeconômicos, encontramos no manual do professor poucos comentários a eles direcionados. Dentre eles, destacamos como contribuidor para a prática e para a formação docente o seguinte:

A expressão variedades urbanas de prestígio (ou normas urbanas de prestígio) vem substituir a noção de língua padrão ou norma culta. Estudos recentes nas ciências da linguagem vêm mostrando que mesmo em se tratando do uso da variedade de prestígio há muita diferença entre o falar 'culto' das diferentes regiões do país. Daí o uso do termo no plural: variedades urbanas de prestígio (FIGUEIREDO, BALTHASAR, GOULART, 2012, p. 200).

Através desse comentário é possível fazer com que o professor que ainda não atentou para essa questão pare para pensar. Afinal, o que é o padrão do português? Ou melhor, do português brasileiro?

A reflexão proposta, então, impede que o professor repasse (esse é o termo) para o aluno a impressão de que as variedades prestigiadas estão isentas de variação, incluindo o padrão que, segundo Faraco, "terá sempre, por coações sociais, um certo efeito unificador sobre as demais normas, não estando, porém, isento também de receber influências dessas mesmas normas" (2004, p. 42). Isso porque variação está presente em toda língua viva (heterogênea e sócio-historicamente situada).

Ressaltamos, porém, a defesa pela inserção de mais comentários destinados aos professores - tanto de caráter teórico-metodológico quanto de sugestões para a prática pedagógica - já que concebemos, assim como Batista (1999), o livro didático como um importante suporte utilizado pelo profissional docente que não deve se configurar como uma "Bíblia". 
Os comentários teórico-metodológicos podem ajudar na formação continuada dos professores e as sugestões fazem com que eles percebam as possibilidades de usos do material, principalmente em função das demandas de seu público-alvo, que é particular possui suas necessidades - e real, por isso não hipotético (como o é para os autores de livro didático).

Reiterando o que foi mencionado anteriormente, a coleção analisada não traz número expressivo de comentários/orientações no manual do professor, embora quando isso seja feito, se dá de forma satisfatória, conforme ilustrado com exemplo anterior sobre a expressão 'variedades urbanas de prestígio'.

Por fim, antes de mais atividades para concluir o capítulo, temos a seguinte proposta de pesquisa (Fig. 10):

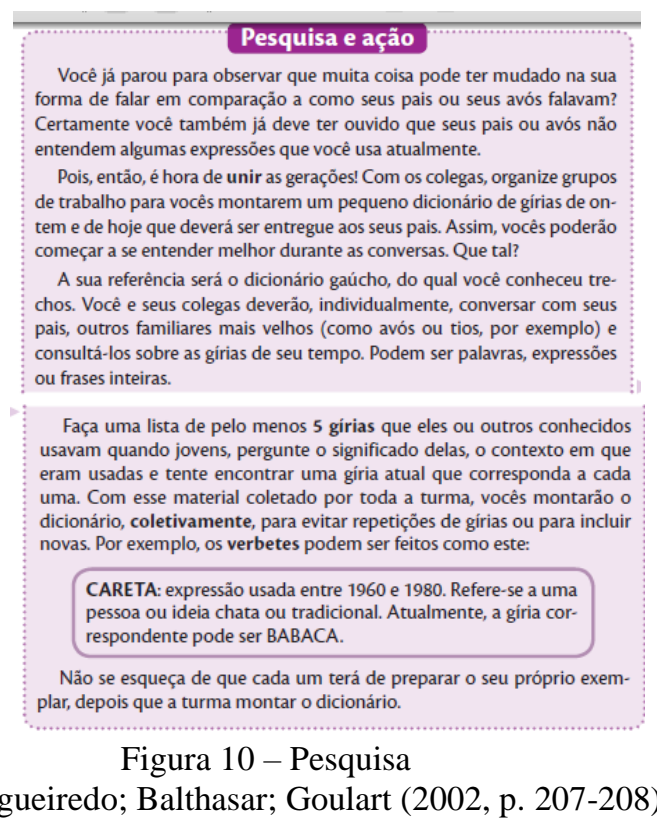

Consideramos essa atividade importante, porque a pesquisa é uma oportunidade para a construção de conhecimentos, em que os alunos assumem papel ativo. No caso da proposta anterior, os alunos são incentivados a irem a campo coletar dados, se organizarem para trabalhar em grupo, se voltarem para suas realidades (uma vez que irão confrontar o seu modo de falar com pessoas próximas, mas de outras gerações). Isso permite, ainda, que seja desconstruída a ideia de que pesquisa escolar é somente copiar e colar informações disponíveis em sites da Internet.

Além disso, é uma forma de associar o conhecimento do eixo de análise linguística trabalhado ao longo do capítulo com o eixo da produção escrita. A proposta relaciona-se com o que foi trabalhado não apenas do ponto de vista temático, mas também do estrutural, ou seja, os alunos irão produzir verbetes assim como os que viram no dicionário gaúcho lido em momento anterior.

\section{Considerações finais}

Como pudemos perceber ao longo deste artigo, muitas contribuições foram dadas para o ensino de português como língua materna no Brasil, sobretudo no que se refere à reflexão sobre variação linguística. Primeiro, os estudos sobre variação, advindos da área da Sociolinguística, foram imprescindíveis para que o fenômeno fosse cientificamente entendido 
com base numa sólida concepção de língua. Depois a reflexão começa a fazer parte da formação inicial e continuada do professor.

O Ministério da Educação também não fica de fora desse debate, fazendo menções explícitas nos Parâmetros Curriculares Nacionais sobre a necessidade de formar um usuário de língua que entenda como o Português tem variedades e como elas devem ser respeitadas. Além disso, acrescenta a temática como um dos critérios de análise para os materiais de Língua Portuguesa no Programa Nacional do Livro Didático.

A análise da coleção selecionada indica também uma evolução no trato didático dado à temática da variação linguística uma vez que apresenta atividades (em sua maioria) que levam à reflexão do aluno, discussões sistemáticas e relacionamento entre os eixos do ensino de português.

Por outro lado, podemos perceber que ainda é necessário na concepção integral do material mais coerência no tratamento com a gramática (que é focada na norma padrão), para que os usos, mesmos das variedades mais prestigiadas, não sejam desconsiderados e fiquem de fora das discussões. Além disso, apesar de ser válida a estratégia de produzir uma parte de um dos livros para contemplar a temática da variação linguística, destacamos a relevância da temática perpassar em mais momentos da coleção.

Por fim, ressaltamos que este estudo se volta para a análise de uma única coleção. Isso suscita a necessidade de outras pesquisas que analisem outras coleções, que investiguem o uso desse e de outros materiais didáticos pelo professor e que reflitam ainda sobre seus processos de formação inicial e continuada.

\section{Referências}

ALKMIM, T. M. Sociolinguística: parte 1. In: MUSSALIM, F.; BENTES. A. C. (Orgs.). Introdução à Linguística: domínios e fronteiras. São Paulo: Cortez, 2005.

BAGNO, M. Falar x comunicar? In: Carta Capital, 03/12/2010. Disponível em <http://www.cartacapital.com.br/carta-fundamental/falar-x-comunicar>. Acesso em: 02 jun. 2013.

Nada na língua é por acaso - por uma pedagogia da variação linguística. São Paulo: Parábola Editorial, 2007.

; STUBBS, M.; GAGNÉ, G. Língua materna: letramento, variação e ensino. São Paulo: Parábola, 2002.

BATISTA, A. A. G. Um objeto variável e instável: textos, impressos e livros didáticos. In: ABREU, Márcia (Org.). Leitura, história e história da leitura. Campinas: Mercado das Letras, 1999, p. 529-575.

BORTONI-RICARDO, S. M. Educação em língua materna: a sociolinguística na sala de aula. São Paulo: Parábola, 2004.

BRASIL. Secretaria de Educação Fundamental. Parâmetros curriculares nacionais: terceiro e quarto ciclos do ensino fundamental: língua portuguesa Brasília: MEC/SEF, 1998.

Parâmetros curriculares nacionais do Ensino Médio. Parte II. Brasília: MEC/Secretaria de Educação Média e Tecnológica, 2000. 
Edital de Convocação 06/2011. Edital de Convocação para o processo de inscrição e avaliação de coleções didáticas para o Programa Nacional do Livro Didático - PNLD 2014. Brasília: Ministério da Educação, Secretaria de Educação Básica, 2011.

- Programa nacional do livro didático (PNLD). Disponível em: http://portal.mec.gov.br/index.php?Itemid=668id=12391option=com_contentview=article Acesso em 22 de julho de 2013.

CHEVALLARD, Y. La transposition didactique: du savoir savant au savoir ensigné. Grenoble: La pensé Sauvage, 1991.

FARACO, C. A. Norma-padrão brasileira - desembaraçando alguns nós. In: BAGNO, M. (Org.) Linguística da Norma. São Paulo: Edições Loyola, 2004.

FERNÁNDEZ, F. M. Principios de Sociolinguística y Sociología del Lenguaje. Barcelona: Ariel, 1998.

FIGUEIREDO, L. de; BALTHASAR, M.; GOULART, S. Singular \& plural: leitura, produção e estudos de linguagem. São Paulo: Moderna, 2012.

GERALDI, J. W. (Org). O texto na sala de aula. São Paulo: Ática 2002.

O livro didático de língua portuguesa: a favor ou contra? Entrevista a Ezequiel Theodoro da Silva. Revista Leitura - teoria e prática, Campinas, ano 06, n. 09, jun. 1987, p. 03-07.

Deslocamentos no ensino: de objetos a práticas; de práticas a objetos. In: Revista Línguas \& Letras (eletrônica) Número Especial - XIX CELLIP - $1^{\circ}$ Semestre de 2011. Disponível em: <http://e-revista.unioeste.br/index.php/linguaseletras/article/view/5510/4183> Acesso em: 15 nov. 2013.

HUDSON, R. La sociolingüística. Barcelona: Anagrama, 1981.

LABOV, W. Padrões sociolinguísticos. São Paulo: Parábola, 2008, p. 63-90.

MARTINS, I. A literatura no ensino médio: quais os desafios do professor? In: BUZEN, C.; MENDONÇA, M. (Orgs.). Português no ensino médio e formação do professor. São Paulo, Parábola Editorial, 2006.

MATOS E SILVA, R. V. Variação, mudança e norma. In: BAGNO, M. (Org.). Linguística da norma. São Paulo: Edições Loyola, 2004, p. 291-316.

POSSENTI, S. Por que (não) ensinar gramática na escola. Campinas: Mercado das Letras, 2002.

ROMAINE, S. El lenguaje en la sociedad. Una introducción a la sociolingüística. España: Ed. Ariel, 1996. 
SACRISTÁN, J. G. O currículo: uma reflexão sobre a prática. Tradução por Ernani F. da F. Rosa. Porto Alegre: Artmed, 2000.

SOARES, M. Português na escola. História de uma disciplina curricular. In: BAGNO, M. (Org.) Linguística da Norma. São Paulo, Loyola, 2002, p. 155-177.

TARALLO, F. A pesquisa sociolinguística. São Paulo: Ática, 2005.

Recebido em: julho de 2014.

Aprovado em: janeiro 2015. 